\title{
Core Handling and Real-Time Non-Destructive Characterization at the Kochi Core Center: An Example of Core Analysis from the Chelungpu Fault
}

\author{
by Weiren Lin, Tetsuro Hirono, En-Chao Yeh, Wataru Tanikawa, and Wonn Soh
}

doi:10.2204/iodp.sd.s01.35.2007

\begin{abstract}
As an example of core analysis carried out in active fault drilling programs, we report the procedures of core handling on the drilling site and non-destructive characterization in the laboratory. This analysis was employed on the core samples taken from Hole B of the Taiwan Chelungpu-fault Drilling Project (TCDP), which penetrated through the active fault that slipped during the $1999 \mathrm{Chi}$-Chi, Taiwan earthquake. We show results of the non-destructive physical property measurements carried out at the Kochi Core Center (KCC), Japan. Distinct anomalies of lower bulk density and higher magnetic susceptibility were recognized in all three fault zones encountered in Hole B. To keep the core samples in good condition before they are used for various analyses is crucial. In addition, careful planning for core handling and core analyses is necessary for successful investigations.
\end{abstract}

\section{Introduction}

An enormous and damaging earthquake (Mw7.6) occurred in west-central Taiwan on 21 September 1999 due to the convergence between the Philippine Sea and Eurasian plates (Shin and Teng, 2001). Its epicenter was located at the vicinity of the country town of Chi-Chi, and the hypocenter was at about $10 \mathrm{~km}$ depth. Abundant teleseismic observation data of the earthquake revealed that the slip displacement and slip velocity increased to as much as $8 \mathrm{~m}$ and $300 \mathrm{~cm} \mathrm{~s}^{-1}$, respectively, but the high-frequency acceleration decreased when the rupture propagated from south to north. For this reason, it was suggested that the fault at the northern segment was lubricated during rupturing (Ma et al., 2003). In order to solve questions about the mechanism of earthquake generation and rupture propagation of the fault, the Taiwan Chelungpu-fault Drilling Project (TCDP) was undertaken (Ma et al., 2006). The drilling site is located in the northern segment where a large surface coseismic displacement occurred.

We jointed the TCDP and transported all the cores of Hole $\mathrm{B}$ taken from the depth range $950-1350 \mathrm{~m}$ to the KCC, Japan to conduct continuous non-destructive measurements. From the excellent scientific results, original papers were published (Hirono et al., 2006a, 2006b), while others have been submitted and some are still under preparation. Here, we only report the procedures of core handling and nondestructive characterization and show several valuable examples of the measurement results.

\section{Core Handling on the Drilling Site}

In order to keep the retrieved core samples in good condition, we paid close attention to i) prevent moisture change while the core was undergoing non-destructive measurement, and until the working half cores were split for individual sampling, ii) avoid contact with oxygen, and iii) keep them cool (but not less than $0^{\circ} \mathrm{C}$ ) to minimize possible chemical reactions and/or biological activity. The most

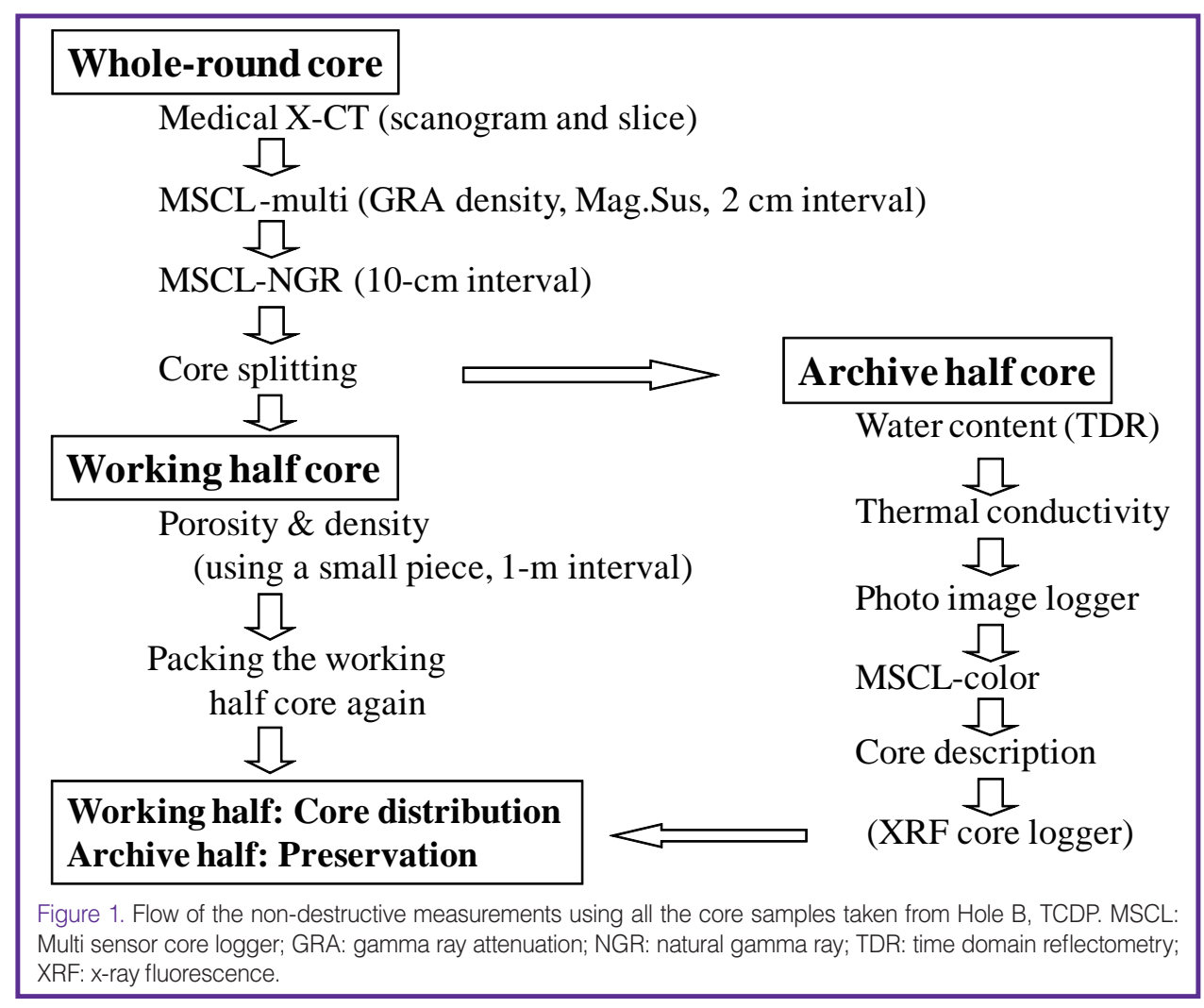


(A) FZB1136

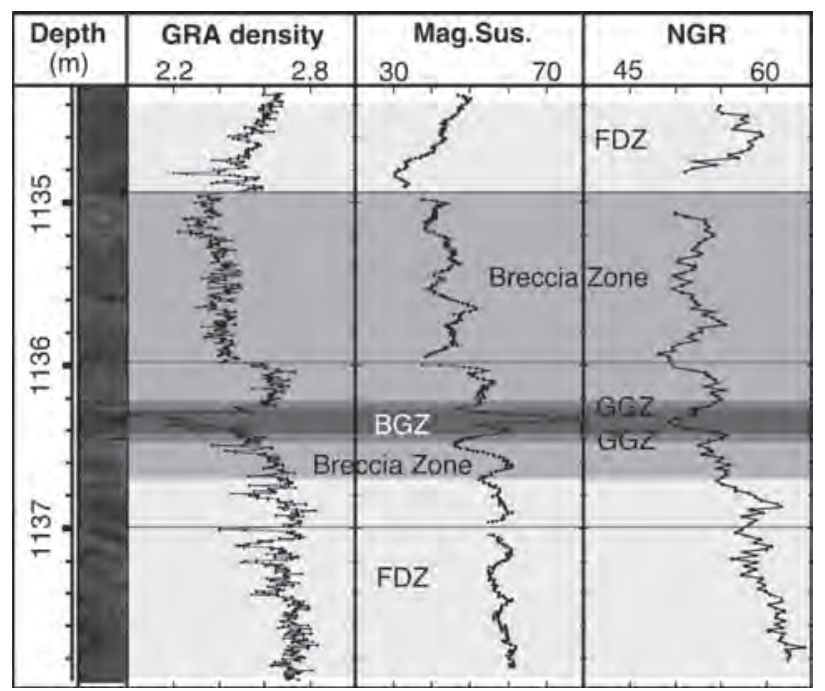

Figure 2 Density, magnetic susceptibility (Mag Sus), and natural gamma ray radiation (NGR) logs from [A FZB1136, [B] FZB1194, and [C] FZB1243. The units are $\mathrm{g} \mathrm{cm}^{-3}, 10-5 \mathrm{SI}$, and cps, respectively. FDZ, fracture-damaged zone; BGZ, block gouge zone; GGZ, gray gouge zone (Hirono et al., 2006b).
(B) FZB1194

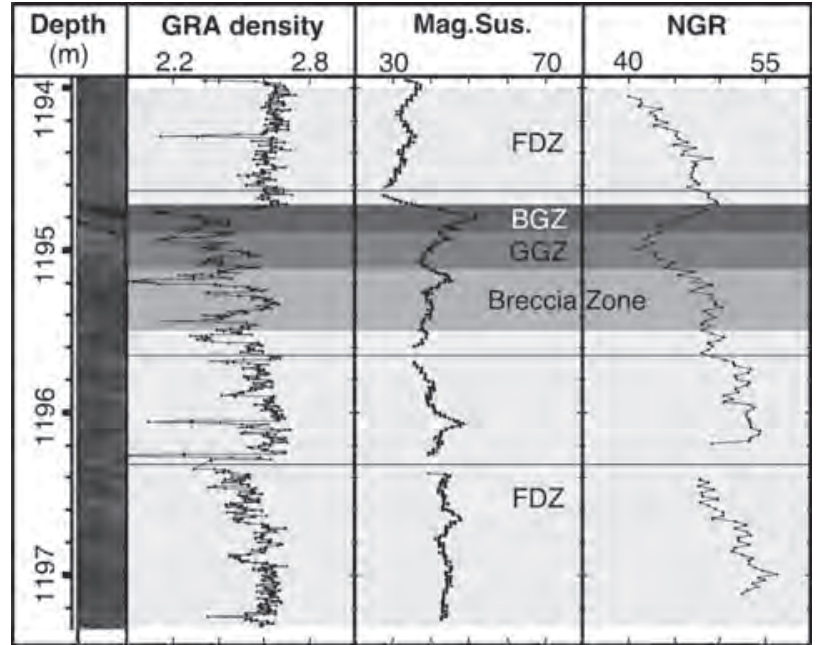

(C) FZB1243

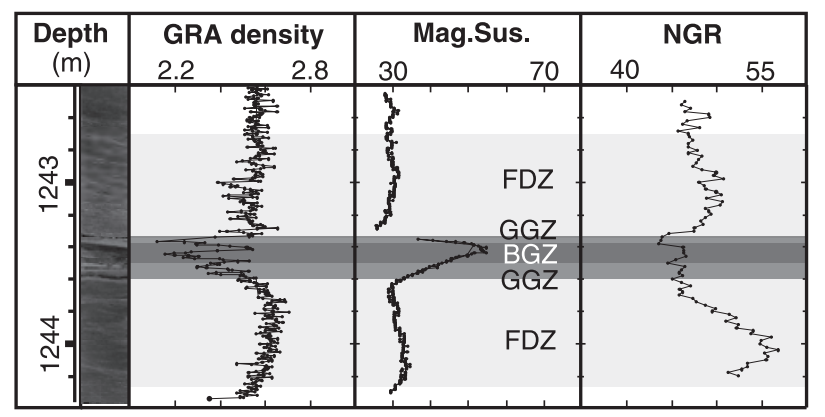

Of course, we paid special attention to fault zone cores in handling them more quickly and carefully.

In order to determine in situ stress orientations and to estimate magnitudes, we did anelastic strain recovery (ASR) measurement using a few cores by the same method as Lin et al (2006). Because the anelastic strain recovers immediately from the in situ stress released by drilling, the measurements have to be conducted as quickly as possible after retrieving the core sample. Therefore, we did it at the on-site laboratory on the drilling site.

\section{Non-Destructive Measurements at the KCC}

Figure 1 shows the work flow for non-destructive measurements on the core of Hole B, TCDP conducted at the KCC. First, an X-ray CT image is taken, while the core sample is still in the aluminum wrapping (ideally without any change in moisture and without oxidation). Next the aluminum packaging was opened and subsequent measurements with the MSCL-multi (Multi-Sensor Core Logger), core splitting and the measurement of thermal conductivity were performed in an optimized process in order to minimize waiting time and avoid moisture vaporization. The physical properties obtained from the measurements are GRA (gamma ray attenuation), wet-bulk density, magnetic susceptibility, NGR (natural gamma ray), porosity, dry-bulk density, volumetric 
water content (by Time Domain Reflectometry, TDR indirect measurement), thermal conductivity, and color indexes ( $\mathrm{L}^{*}$, $a^{*}, b^{*}$ which correspond to brightness, chromaticity of redgreen and blue-yellow, respectively). Moreover, x-ray CT scanograms, slice images on the whole-round core, and optical pictures on split surfaces are available. Unfortunately, the accuracy and reliability of P-wave velocity and electrical resistivity data by the MSCL were low, so that the data need further calibration and discussion before interpretation. In addition, mainly due to a problem with poor smoothness of the split core surface, the analyses to identify chemical elements by using XRF (x-ray fluorescence) core logger are also pending.

\section{Examples of Measurement Results}

(1) MSCL measurement results

The Hole B drilling penetrated the Chelungpu fault and recovered core samples ranging from about $950 \mathrm{~m}$ to $1350 \mathrm{~m}$ in vertical depth. Three fault zones-FZB1136 (fault zone at about 1136 m depth in Hole B), FZB1194, and FZB1243were recognized in the core samples on-site as series within the Chelungpu fault system. The results of MSCL measurements (see Fig. 2) revealed distinct anomalies, lower wetbulk densities, and higher magnetic susceptibilities within black gouge zones in all three fault zones (Hirono et al., 2006b). Higher magnetic susceptibilities can indicate that they have experienced intense shearing and/or frictional heating. The non-destructive continuous physical property measurements can provide important preliminary knowledge for understanding the faulting mechanism of the 1999 ChiChi earthquake.

\section{(2) An ASR measurement result}

We showed an example of the application of the ASR method for stress measurement on the drill core of the TCDP hole penetrated into the active Chelungpu fault. The anelastic strains of a drill core specimen in nine directions, including six independent directions, were measured using wire strain gauges after having retrieved the core from the borehole to ground level (Lin et al., 2007). The core specimen was sandstone taken from a depth of $592 \mathrm{~m}$ in Hole A. Acquired anelastic strains (Fig. 3A) were extensions - they reached several hundred microstrains, which is a level high enough to ensure satisfactory measurement accuracy. These strains were used for a three-dimensional analysis to determine the orientations and estimation of the magnitudes of the principal in situ stresses. The orientations determined by the strain data are shown in Fig. 3B. The estimated magnitudes of the maximum, intermediate, and minimum principal stresses are 14.6 $\mathrm{MPa}, 12.6 \mathrm{MPa}$, and $12.1 \mathrm{MPa}$, respectively. The obtained results can be considered as valid; consequently, it can be said that the anelastic strain recovery measurement is well suited to the task of directly determining the orientations of principal in situ stresses and of estimating the magnitude of the stresses at great depth. The results of theses stress measurements suggest both the orientation and magnitude of current stress at the vicinity of the Chelungpu fault in TCDP holes might be influenced by the fault rupturing.

\section{Summary}

As an example of core analysis carried out for the active fault drilling program, we reported the procedures of core handling and non-destructive characterization employed for the core samples taken from Hole B of the Taiwan Chelungpufault Drilling Project. Then, we showed two examples of the results; one is the non-destructive physical property measurements carried out at the KCC, Japan. Distinct anomalies of lower bulk density and higher magnetic susceptibilities were recognized in all three fault zones encountered in Hole B. Another example is carried out on the drilling site. Anelastic strain was measured by using a core sample after the in situ stress was released. It shows the anelastic strain result was satisfactory and can be used for determining threedimensional principal stress orientations and estimating their magnitudes. Needless to say, the studies using core samples are important for scientific drilling, specifically for active fault drilling programs. However, it is more important
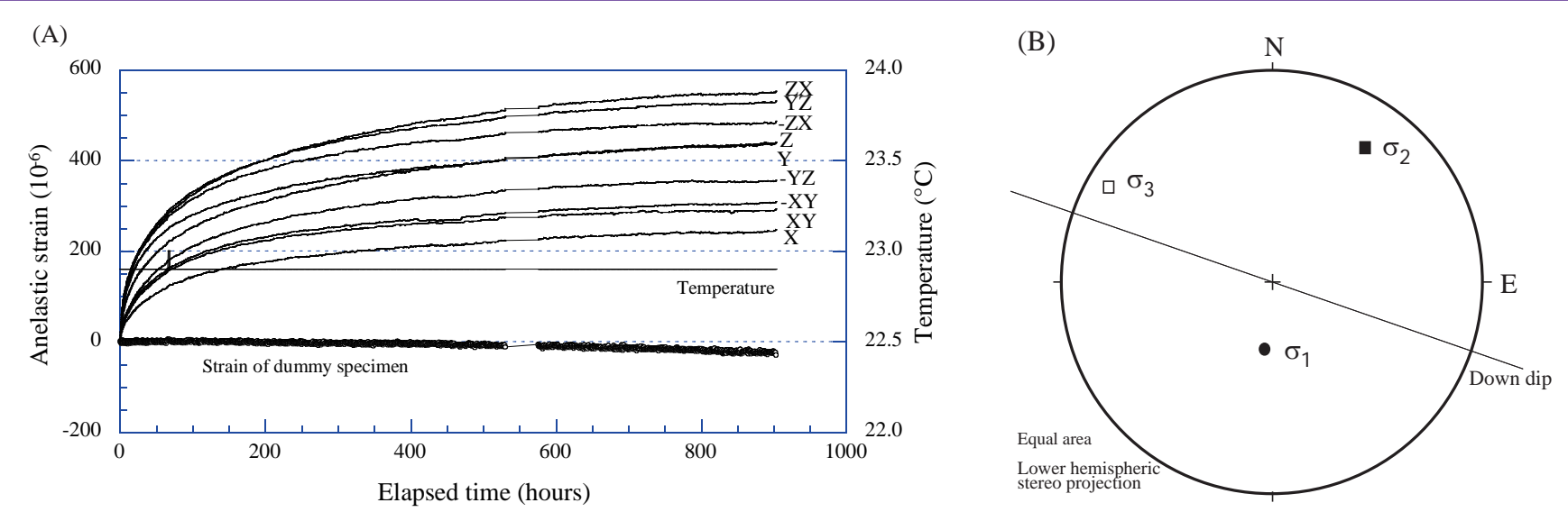

Figure 3. [A] An example of anelastic strain of a sandstone core sample from a depth of about $600 \mathrm{~m}$ in Hole A. [B] Three-dimensional in situ stress orientation determined by the ASR data shown in [A] (Lin et al., 2007). 
to keep cores in the good conditions before they are used for various analyses. Careful planning for core handling and core analysis is necessary for successful investigations.

\section{Acknowledgements}

First, we thank the principal investigators, Y.-B. Tsai, C.Y. Wang, K.-F. Ma, S.-R. Song, and J.-H. Hung of TCDP for giving us the opportunity to use all the cores of Hole-B for the measurements at KCC. We also thank the working group in Japan including Y. Hashimoto, H. Sone, L-W. Kuo, O. Matsubayashi, K. Aoike, H. Ito, M. Kinoshita, M. Murayama, and other colleagues from CDEX/JAMSTEC and Marine Work Japan, Ltd., and many students from Kochi University. We are very grateful for much kind cooperation of B. Lin and Y. Wei and others of the drilling company, as well as Taiwanese assistants and students from NCU and NTU during the handling of cores on site.

\section{References}

Hirono, T., Ikehara, M., Otsuki, K., Mishima, T., Sakaguchi, M., Soh, W., Omori, M., Lin, W., Yeh, E.-C., Tanikawa, W., and Wang, C.-Y., 2006a. Evidence of frictional melting from disk-shaped black material, discovered within the Taiwan Chelungpu fault system. Geophys. Res. Lett., 33:L19311, doi:10.1029/ 2006GL027329.

Hirono, T., Lin, W., Yeh, E.-C., Soh, W., Hashimoto, Y., Sone, H., Matsubayashi, O., Aoike, K., Ito, H., Kinoshita, M., Murayama, M., Song, S.-R., Ma, K.-F., Hung, J.-H., Wang, C.-Y., and Tsai, Y.-B., 2006b. High magnetic susceptibility of fault gouge within Taiwan Chelungpu fault: Nondestructive continuous measurements of physical and chemical properties in fault rocks recovered from Hole B, TCDP. Geophys. Res. Lett., 33:L15303, doi:10.1029/2006GL026133.

Lin, W., Kwasniewski, M., Imamura, T., and Matsuki, K., 2006. Determination of three-dimensional in situ stresses from anelastic strain recovery measurement of cores at great depth. Tectonophysics, 426:221-238, doi:10.1016/j. tecto.2006.02.019.

Lin, W., Yeh, E.-C., Ito, H., Hirono, T., Soh, W., Wang, C.-Y., Ma, K.-F., Hung, J.H., and Song, S.-R., 2007. Preliminary results of stress measurement by using drill cores of TCDP Hole-A: An application of anelastic strain recovery method to threedimensional in situ stress determination, Terr. Atm. Ocean Sci., 18:379-393, doi:10.3319/TAO.2007.18.2.379(TCDP).

Ma, K.-F., Brodsky, E.E., Mori, J., Ji, C., Song, T.-R.A., and Kanamori, H., 2003. Evidence for fault lubrication during the 1999 ChiChi, Taiwan, earthquake (Mw7.6), Geophys. Res. Lett., 30:1244-1247, doi:10.1029/2002GL015380.

Ma, K-F, Tanaka, H., Song, S.-R., Wang, C.-Y., Hung, J.-H., Tsai, Y.-B., Mori, J., Song, Y.-F., Yeh, E.-C., Soh, W., Sone, H., Kuo, L.W., and $\mathrm{Wu}, \mathrm{H} .-\mathrm{Y} ., 2006$. Slip zone and energetics of a large earthquake from the Taiwan Chelungpu-fault drilling project. Nature, 444:473-476, doi:10.1038/nature05253.

Shin, T-C. and Teng, T.-L., 2001. An overview of the 1999 Chi-Chi, Taiwan, Earthquake. Bull. Seismol. Soc. Am., 91:895-913, doi:10.1785/0120000738.

\section{Authors}

Weiren Lin, Wataru Tanikawa, and Wonn Soh, Kochi Institute for Core Sample Research, Japan Agency for Marine-Earth Science and Technology, B200 Monobe, Nankoku, Kochi, 783-8502 Japan, e-mail: lin@jamstec.go.jp. Tetsuro Hirono, Department of Earth and Space Science, Graduate School of Science, Osaka University, Toyonaka 560-0043, Osaka, Japan.

En-Chao Yeh, National Taiwan University, No.1, Dec. 4, Roosevelt Road, Taipei, 106147, Taiwan (R.O.C.). 